\title{
NQR and DSC Studies on Structural Phase Transitions and Lattice Stability in Some Tetrabromozincate(II) Compounds $\mathbf{A}_{2} \mathbf{Z n B r}_{4}$
}

\author{
Keizo Horiuchi, Hideta Ishihara ${ }^{\mathrm{a}}$, Naoko Hatano ${ }^{\mathrm{a}}$, Syuntaroh Okamoto, \\ and Tohru Gushiken \\ Faculty of Science, University of the Ryukyus, Nishihara-cho, Okinawa 903-0213, Japan \\ ${ }^{a}$ Faculty of Culture and Education, Saga University, Honjo-machi 1, Saga 840-8502, Japan \\ Reprint requests to Dr. K. H.; E-mail: horiuchi@sci.u-ryukyu.ac.jp
}

Z. Naturforsch. 57 a, 425-430 (2002); received January 23, 2002

Presented at the XVIth International Symposium on Nuclear Quadrupole Interactions, Hiroshima, Japan, September 9-14, 2001.

\begin{abstract}
The temperature dependence of ${ }^{81} \mathrm{Br}$ NQR frequencies in some tetrabromozincate(II) compounds, pyridinium tetrabromozincate(II) $(\mathrm{pyH})_{2} \mathrm{ZnBr}_{4}$, 4-picolinium tetrabromozincate(II) (4$\mathrm{piH})_{2} \mathrm{ZnBr}_{4}$, 2,6-lutidinium tetrabromozincate(II) $(2,6-\mathrm{luH})_{2} \mathrm{ZnBr}_{4}$ and guanidinium tetrabromozincate(II) $(\mathrm{guH})_{2} \mathrm{ZnBr}_{4}$, were measured between $77 \mathrm{~K}$ and temperatures where signals faded out. All compounds exhibited four NQR signals over the whole temperature range investigated. Moreover, DSC was measured between about $130 \mathrm{~K}$ and melting points. (4-piH) ${ }_{2} \mathrm{ZnBr}_{4}$ and $(\mathrm{guH})_{2} \mathrm{ZnBr}_{4}$ showed no structural phase transition, while $(\mathrm{pyH})_{2} \mathrm{ZnBr}_{4}$ and $(2,6-\mathrm{luH})_{2} \mathrm{ZnBr}_{4}$ showed a single phase transition. The values of transition entropies obtained suggest that these transitions are of the order-disorder type. The nature of these transitions and the lattice stability in the present compounds were discussed.
\end{abstract}

Key words: NQR; DSC; Phase Transition; Transition Entropy; Tetrabromozincate.

\section{Introduction}

We have studied molecular motions and structural phase transitions in $\mathrm{A}_{2} \mathrm{ZnX}_{4}$ compounds ( $\mathrm{X}=\mathrm{Cl}$ and Br) by NQR, NMR, DSC, DTA, X-ray diffraction and electrical conductivity [1 - 7]. In the present study, we adopted plane molecular unities of pyridinium and guanidinium ions as $\mathrm{A}$ in $\mathrm{A}_{2} \mathrm{ZnBr}_{4}$, because such $\mathrm{A}_{2} \mathrm{BX}_{4}$ compounds have seldom been studied so far. Pyridinium compounds often undergo structural phase transitions driven by orientational disordering about the axis perpendicular to the molecular plane of a pyridinium ion $\mathrm{C}_{5} \mathrm{H}_{5} \mathrm{NH}^{+}$[8 - 10], which has a planar ring structure very similar to a benzene molecule $\mathrm{C}_{6} \mathrm{H}_{6}$. Hence, pyridinium tetrabromozincate(II) $\left(\mathrm{C}_{5} \mathrm{H}_{5} \mathrm{NH}\right)_{2} \mathrm{ZnBr}_{4}$ is expected to show order-disorder transitions. However, if methyl groups are introduced into a pyridinium ion, it is expected that the groups will hinder the ion from disordering about the axis $[8,11]$. 4-picolinium and 2,6-lutidinium ions have one and two methyl groups, respectively. Moreover, a guanidinium ion $\mathrm{C}\left(\mathrm{NH}_{2}\right)_{3}^{+}$ can take disorderd sites in the crystalline state, because it can reorient about the axis perpendicular to a molecular plane [12-14]. In the present investigation, $\left(\mathrm{C}_{5} \mathrm{H}_{5} \mathrm{NH}\right)_{2} \mathrm{ZnBr}_{4}$, 4-picolinium tetrabromozincate(II) (4- $\left.\mathrm{CH}_{3} \mathrm{C}_{5} \mathrm{H}_{4} \mathrm{NH}\right)_{2} \mathrm{ZnBr}_{4}$, 2,6-lutidinium tetrabromozincate(II) $\quad\left(2,6-\left[\mathrm{CH}_{3}\right]_{2} \mathrm{C}_{5} \mathrm{H}_{3} \mathrm{NH}\right)_{2} \mathrm{ZnBr}_{4}$ and guanidinium tetrabromozincate(II) $\left(\mathrm{C}\left[\mathrm{NH}_{2}\right]_{3}\right)_{2}-$ $\mathrm{ZnBr}_{4}$ were studied by ${ }^{81} \mathrm{Br} \mathrm{NQR}$ and differential scanning calorimetry (DSC).

In this paper, we will abbreviate $\left(\mathrm{C}_{5} \mathrm{H}_{5} \mathrm{NH}\right)$, (4$\left.\mathrm{CH}_{3} \mathrm{C}_{5} \mathrm{H}_{4} \mathrm{NH}\right),\left(2,6-\left[\mathrm{CH}_{3}\right]_{2} \mathrm{C}_{5} \mathrm{H}_{3} \mathrm{NH}\right)$, and $\left(\mathrm{C}\left[\mathrm{NH}_{2}\right]_{3}\right)$ as (pyH), (2-piH), (2,6-luH), and (guH), respectively.

\section{Experimental}

Pyridine and $\mathrm{ZnBr}_{2}$ were added to a $\mathrm{HBr}$ solution with a stoichiometric ratio. By slow evaporation of solvents in a desiccator over $\mathrm{P}_{2} \mathrm{O}_{5}$ at room temperature, a polycrystalline sample of $(\mathrm{pyH})_{2} \mathrm{ZnBr}_{4}$ was obtained. The other samples were prepared accordingly. All crystals obtained are colorless and hygroscopic. Elemental analyses for $\mathrm{C}, \mathrm{H}$, and $\mathrm{N}$ were car- 
Table 1. Chemical analysis (wt.\%) of tetrabromozincate(II) compounds.

\begin{tabular}{lcccccc}
\hline Compound & \multicolumn{2}{c}{$\mathrm{C}$} & \multicolumn{2}{c}{$\mathrm{H}$} & \multicolumn{2}{c}{$\mathrm{N}$} \\
& \multicolumn{5}{c}{ Calcd. Obsd. Calcd. Obsd. Calcd. Obsd. } \\
\hline$\left(\mathrm{C}_{5} \mathrm{H}_{5} \mathrm{NH}\right)_{2} \mathrm{ZnBr}_{4}$ & 22.02 & 21.98 & 2.21 & 2.24 & 5.13 & 5.16 \\
$\left(4-\mathrm{CH}_{3} \mathrm{C}_{5} \mathrm{H}_{4} \mathrm{NH}\right)_{2} \mathrm{ZnBr} \mathrm{Zn}_{4}$ & 25.14 & 25.18 & 2.81 & 2.78 & 4.88 & 4.92 \\
$\left(2,6-\left[\mathrm{CH}_{3}\right]_{2} \mathrm{C}_{5} \mathrm{H}_{3} \mathrm{NH}\right)_{2}-$ & 27.96 & 27.67 & 3.35 & 3.46 & 4.65 & 4.63 \\
$\mathrm{ZnBr}_{4}$ & & & & & & \\
$\left(\mathrm{C}\left[\mathrm{NH}_{3}\right]_{3}\right)_{2} \mathrm{ZnBr}_{4}$ & 4.75 & 5.11 & 2.39 & 2.42 & 16.63 & 16.73 \\
\hline
\end{tabular}

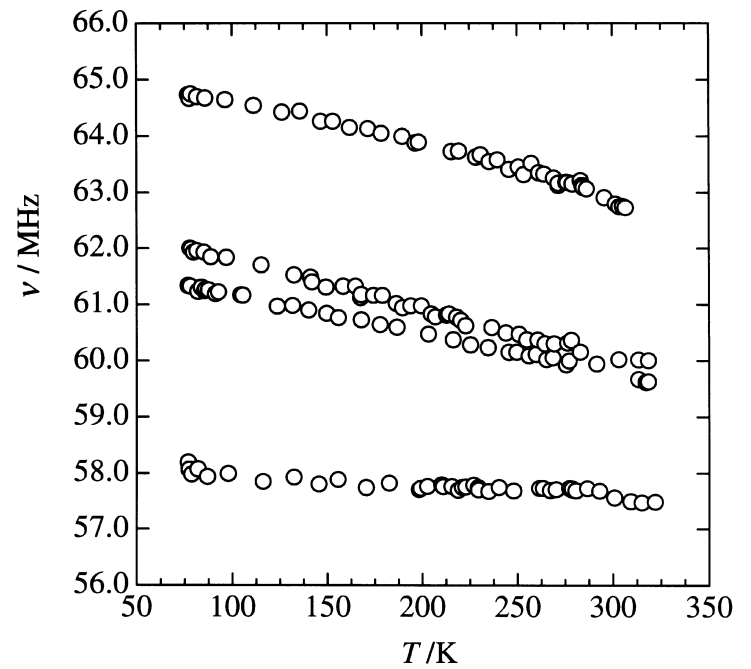

Fig. 1. Temperature dependence of ${ }^{81} \mathrm{Br} \mathrm{NQR}$ frequencies in pyridinium tetrabromozincate(II) $\left(\mathrm{C}_{5} \mathrm{H}_{5} \mathrm{NH}\right)_{2} \mathrm{ZnBr}_{4}$.

ried out for these samples and the results are listed in Table 1.

The ${ }^{79,81} \mathrm{Br}$ NQR spectra were recorded with an NQR spectrometer working in the super-regenerative mode and resonance frequencies were determined by counting techniques. The sample temperature was controlled by a temperature-regulated nitrogen-gas flow and measured by a copper-constantan thermocouple.

A differential scanning calorimeter DSC220 with a disk-station SSC5200 from Seiko Instruments Inc. was used for thermal measurements. Before DSC measurements were performed, samples were pulverized and then dried over silica gel or $\mathrm{P}_{2} \mathrm{O}_{5}$ in a desiccator. Samples of around $10 \mathrm{mg}$ were employed and the heating and cooling rates were usually set at 10 and $5 \mathrm{~K} \mathrm{~min}^{-1}$, respectively. The measurements were carried out under an atmosphere of dry $\mathrm{N}_{2}$ gas with a flow rate of about $40 \mathrm{ml} \mathrm{min}^{-1}$ and repeated more than three times.
Table 2. ${ }^{81} \mathrm{Br} \mathrm{NQR}$ frequencises at several temperatures and temperature coefficients $K_{\nu}=\Delta \nu / \Delta T$ between $77 \mathrm{~K}$ and room temperature.

\begin{tabular}{|c|c|c|c|}
\hline$\nu / \mathrm{MHz}(T / \mathrm{K})$ & $\nu / \mathrm{MHz}(T / \mathrm{K})$ & $\nu / \mathrm{MHz}(T / \mathrm{K})$ & $K_{\nu} / \mathrm{kHz} \mathrm{K}^{-1}$ \\
\hline \multicolumn{4}{|c|}{$\left(\mathrm{C}_{5} \mathrm{H}_{5} \mathrm{NH}\right)_{2} \mathrm{ZnBr}_{4}:$} \\
\hline 64.731(77) & $63.152(279)$ & $62.727(307)$ & -7.82 \\
\hline $61.998(77)$ & $60.359(278)$ & $60.000(319)$ & -8.15 \\
\hline $61.331(77)$ & 59.993(277) & $59.623(319)$ & -6.69 \\
\hline $58.059(77)$ & $57.715(279)$ & $57.479(322)$ & -1.70 \\
\hline \multicolumn{4}{|c|}{$\left(4-\mathrm{CH}_{3} \mathrm{C}_{5} \mathrm{H}_{4} \mathrm{NH}\right)_{2} \mathrm{ZnBr}_{4}$ : } \\
\hline $67.259(77)$ & $65.51(281)$ & $65.14(316)$ & -8.57 \\
\hline 60.794(77) & $59.84(296)$ & $59.75(315)$ & -4.4 \\
\hline $58.995(77)$ & 57.71(298) & $57.66(318)$ & -5.81 \\
\hline $57.150(77)$ & $55.77(299)$ & $55.75(322)$ & -6.22 \\
\hline \multicolumn{4}{|c|}{$\left(2,6-\left[\mathrm{CH}_{3}\right]_{2} \mathrm{C}_{5} \mathrm{H}_{3} \mathrm{NH}\right)_{2} \mathrm{ZnBr}_{4}:$} \\
\hline $67.720(77)$ & $66.78(298)$ & $66.59(325)$ & -4.25 \\
\hline $65.708(77)$ & $64.60(296)$ & $64.39(329)$ & -5.06 \\
\hline $64.596(77)$ & $62.10(298)$ & $61.75(330)$ & -11.3 \\
\hline 47.668(77) & 47.61(299) & $47.63(328)$ & -0.2 \\
\hline \multicolumn{4}{|c|}{$\left(\mathrm{C}\left[\mathrm{NH}_{3}\right]_{3}\right)_{2} \mathrm{ZnBr}_{4}:$} \\
\hline $65.351(77)$ & 63.14(297) & $62.90(317)$ & -10.1 \\
\hline $61.837(77)$ & 58.84(298) & & -13.6 \\
\hline $58.861(77)$ & $57.44(296)$ & $57.28(320)$ & -6.49 \\
\hline $53.979(77)$ & 54.84(298) & $54.86(304)$ & +3.9 \\
\hline
\end{tabular}

\section{Results}

\section{Nuclear Quadrupole Resonance}

${ }^{81} \mathrm{Br}$ NQR frequencies were measured as a function of temperature between $77 \mathrm{~K}$ and temperatures where signals fade out. The results are shown in Figs. 1 - 4 and their numerical values at some temperatures along with temperature coefficients $\Delta \nu / \Delta T$ are given in Table 2. All compouds gave four ${ }^{81} \mathrm{Br}$ NQR signals with the same intensity ratio and, as can be seen from figures, their frequencies decrease in most cases proportional to the temperature on heating except for the following signals. The lowest-frequency line of $(\mathrm{guH})_{2} \mathrm{ZnBr}_{4}$ exhibits a positive temperature variation. The lowest-frequency line of $(2,6-\mathrm{luH})_{2} \mathrm{ZnBr}_{4}$ is almost independent of temperature. These temperature dependencies in NQR frequencies are related to $\mathrm{NH} \cdot . \mathrm{Br}$ hydrogen bonds between cations and anions $[15,16]$. Furthermore, a slight but anomalous variation in the temperature dependence of resonance lines was observed around $280 \mathrm{~K}$ for $(\mathrm{pyH})_{2} \mathrm{ZnBr}_{4}$. That is, a temperature coefficient of the second-highest-frequency line changes discontinuously around $280 \mathrm{~K}$; the lowest-frequency line is almost temperature-independent, while around $280 \mathrm{~K}$ the frequency is tem- 


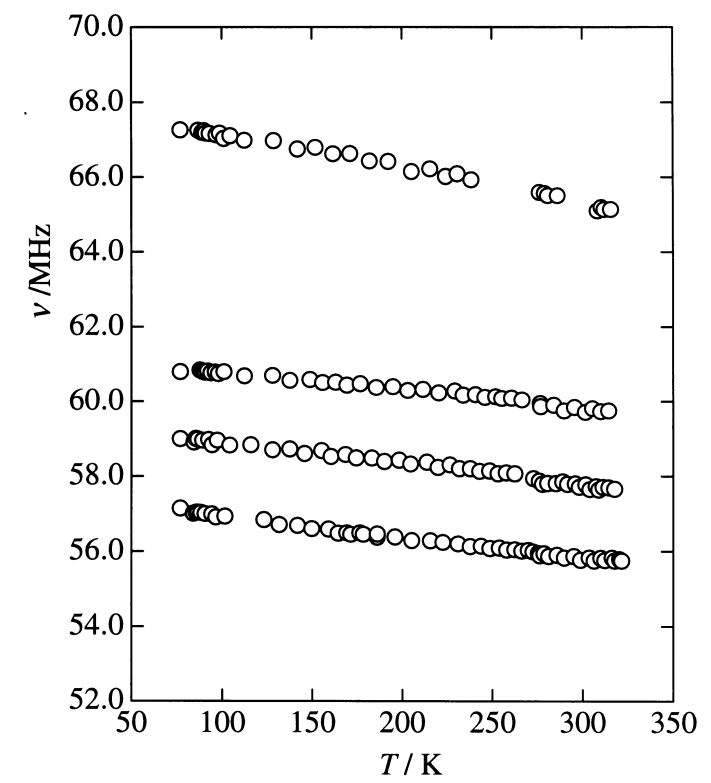

Fig. 2. Temperature dependence of ${ }^{81} \mathrm{Br} \mathrm{NQR}$ frequencies in 4-picolinium tetrabromozincate(II) $\left(4-\mathrm{CH}_{3} \mathrm{C}_{5} \mathrm{H}_{4} \mathrm{NH}\right)_{2}-$ $\mathrm{ZnBr}_{4}$.

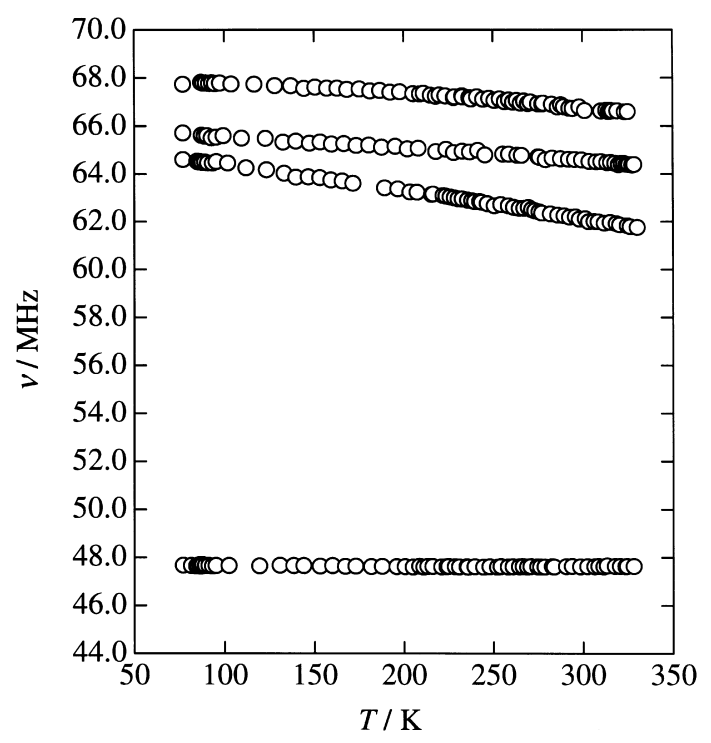

Fig. 3. Temperature dependence of ${ }^{81} \mathrm{Br} \mathrm{NQR}$ frequencies in 2,6-lutidinium tetrabromozincate(II) $\left(2,6-\left[\mathrm{CH}_{3}\right]_{2} \mathrm{C}_{5} \mathrm{H}_{3}-\right.$ $\mathrm{NH})_{2} \mathrm{ZnBr}_{4}$

perature-dependent and about $200 \mathrm{kHz}$ of shift was observed.

The crystal structure of $(\mathrm{guH})_{2} \mathrm{ZnBr}_{4}$ is reported to be triclinic with space group P1 [17]. There is

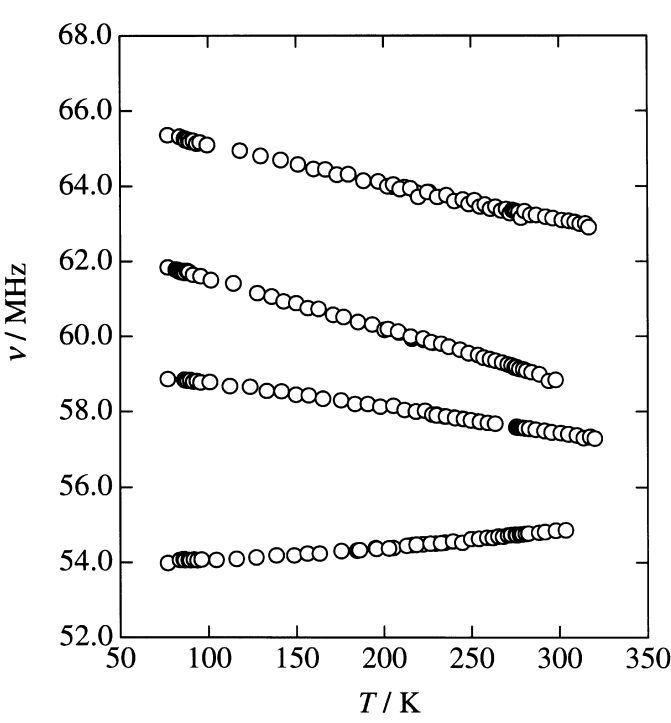

Fig. 4. Temperature dependence of ${ }^{81} \mathrm{Br} \mathrm{NQR}$ frequencies in guanidinium tetrabromozincate(II) $\left(\mathrm{C}\left[\mathrm{NH}_{3}\right]_{3}\right)_{2} \mathrm{ZnBr}_{4}$

one crystallographically nonequivalent anion in a unit cell and the $\mathrm{ZnBr}_{4}^{2-}$ ion adopts a shape of a slightly distorted tetrahedron. Although crystal structures of the three other compounds are unknown, it is assumed that those anions form isolated $\mathrm{ZnBr}_{4}^{2-}$ tetrahedra, as this coordination is exclusive for $\mathrm{ZnX}_{4}$ complexes in the solid state. In that case, four resonance signals should be assigned to four bromine atoms in the same tetrahedron. All resonance lines fade out at about 320 - $330 \mathrm{~K}$, which can be explained by the fluctuation of electric field gradients at bromine nuclei caused by reorientational motions of anions [2]. However, the fade-out of resonance lines in some crystals may be ascribed to phase transitions. DSC measurements will give us the information on phase transitions above room temperature.

\section{Differential Scanning Calorimetry}

DSC measurements were carried out between about $130 \mathrm{~K}$ and melting points. The results are summerized in Table 3. All compounds melted below $500 \mathrm{~K}$. A heat anomaly due to a structural phase transition was detected in $(\mathrm{pyH})_{2} \mathrm{ZnBr}_{4}$ and $(2,6-$ $\mathrm{luH})_{2} \mathrm{ZnBr}_{4}$. A virgin sample of $(\mathrm{pyH})_{2} \mathrm{ZnBr}_{4}$ sometimes showed a heat anomaly not at $342 \mathrm{~K}$ but at $360 \mathrm{~K}$. However, after the second measurement. The heat anomaly always appeared at $342 \mathrm{~K}$. In a previous DTA measurement, a heat anomaly was detected at 
Table 3. Transition temperatures $T_{\mathrm{c}}$, orders of the transitions, transition enthalpies $\Delta H$, transition entropies $\Delta S$ and thermal hysteresis $\Delta T_{\mathrm{c}}$ for phase transitions in tetrabromozincate(II) compounds.

\begin{tabular}{|c|c|c|c|c|}
\hline $\begin{array}{l}T_{\mathrm{c}} \\
(\mathrm{K})\end{array}$ & Order & $\begin{array}{l}\Delta H \\
\left(\mathrm{~kJ} \mathrm{~mol}^{-1}\right)\end{array}$ & $\begin{array}{l}\Delta S \\
\left(\mathrm{~J} \mathrm{~K}^{-1} \mathrm{~mol}^{-1}\right)\end{array}$ & $\begin{array}{l}\Delta T_{\mathrm{c}} \\
(\mathrm{K})\end{array}$ \\
\hline \multicolumn{5}{|c|}{$\left(\mathrm{C}_{5} \mathrm{H}_{5} \mathrm{NH}\right)_{2} \mathrm{ZnBr}_{4}:$} \\
\hline $\begin{array}{l}342 \pm 1 \\
448 \pm 1\end{array}$ & $\begin{array}{l}1 \text { st } \\
\text { (fusion) }\end{array}$ & $\begin{array}{l}6.3 \pm 0.2 \\
28 \pm 1\end{array}$ & $\begin{array}{l}18 \pm 0.5 \\
62 \pm 2\end{array}$ & $\begin{array}{l}43 \pm 2 \\
25 \pm 4\end{array}$ \\
\hline \multicolumn{5}{|c|}{$\left(4-\mathrm{CH}_{3} \mathrm{C}_{5} \mathrm{H}_{4} \mathrm{NH}\right)_{2} \mathrm{ZnBr}_{4}$ : } \\
\hline \multicolumn{4}{|c|}{$\left(2,6-\left[\mathrm{CH}_{3}\right]_{2} \mathrm{C}_{5} \mathrm{H}_{3} \mathrm{NH}\right)_{2} \mathrm{ZnBr}_{4}:$} & $43.5 \pm 1$ \\
\hline $\begin{array}{l}327 \pm 1 \\
493 \pm 1\end{array}$ & $\begin{array}{l}1 \mathrm{st} \\
\text { (fusion) }\end{array}$ & $\begin{array}{l}5 \pm 1 \\
42 \pm 1\end{array}$ & $\begin{array}{l}15 \pm 2 \\
85 \pm 2\end{array}$ & $\begin{array}{c}* \\
81 \pm 5\end{array}$ \\
\hline$\left(\mathrm{C}\left[\mathrm{NH}_{3}\right]\right.$ & )$_{2} \mathrm{ZnBr}_{4}$ : & $311+05$ & $70+1$ & $48+2-3$ \\
\hline
\end{tabular}

* an endothermic peak was not observed on cooling.

about $420 \mathrm{~K}$ [18], which can not be confirmed in the present DSC measurement.

\section{Discussion}

\section{Structural Phase Transitions}

Structural phase transitions observed in $(\mathrm{pyH})_{2}$ $\mathrm{ZnBr}_{4}$ and $(2,6-\mathrm{luH})_{2} \mathrm{ZnBr}_{4}$ are recognized as firstorder because of thermal hysteresis in the heat anomalies. In additon, the values of transition entropies suggest an order-disorder type.

A phase transition in $(\mathrm{pyH})_{2} \mathrm{ZnBr}_{4}$ is probably driven by orientational disordering of a pyridinium ion about the axis perpendicular to a ring plane. If this type of transition occurs in $(\mathrm{pyH})_{2} \mathrm{ZnBr}_{4}$, a transition entropy experimentally observed can be interpreted in terms of Boltzmann's principle

$$
\Delta S=2 R \ln \left(N_{\mathrm{h}} / N_{1}\right)
$$

where, $N_{\mathrm{h}}$ and $N_{1}$ are the number of distinguishable orientations allowed in high- and low-temperature phases, respectively. An observed $\Delta S$ value of $18 \mathrm{~J} \mathrm{~K}^{-1} \mathrm{~mol}^{-1}$ leads to $N_{\mathrm{h}} / N_{\mathrm{l}}=3$. This means that if pyridine ions are ordered in a low-temperature phase, they are disorderd among three sites in a hightemperature phase, and if pyridine ions are already disordered in a low-temperature phase, for example, in two-fold orientations, they are six-fold disordered in a high-temperature phase.
No heat anomaly was observed around $280 \mathrm{~K}$ for $(\mathrm{pyH})_{2} \mathrm{ZnBr}_{4}$. Since a displacive transition generally show a small transition enthalpy, sometimes it cannot be detected by thermal measurements. However, NQR is very sensitive to a displacive phase transition as well as an order-disorder transition. Hence, a phase transition associated with a small displacement of $\mathrm{ZnBr}_{4}$ may occur around $280 \mathrm{~K}$, because a temperature variation of NQR frequencies is unusual around that point.

The transition entropy observed in $(2,6-\mathrm{luH})_{2}$ $\mathrm{ZnBr}_{4}$ has a relatively large value of $15 \mathrm{~J} \mathrm{~K}^{-1} \mathrm{~mol}^{-1}$. If anions are orientationally disordered, Boltzmann's principle leads to $N_{\mathrm{h}} / N_{\mathrm{l}}=6$. A possibility of an orientational disorder of $\mathrm{ZnBr}_{4}$ is reported for $\left(\mathrm{N}\left[\mathrm{CH}_{3}\right]_{4}\right)_{2} \mathrm{ZnBr}_{4}$ and the isomorphous compounds $\left(\mathrm{N}\left[\mathrm{CH}_{3}\right]_{4}\right)_{2} \mathrm{MCl}_{4}(\mathrm{M}=\mathrm{Co}, \mathrm{Ni}, \mathrm{Cu}$, and $\mathrm{Zn})$ [19]. In these cases, however, a tetrahedron is considered to be disordered between two close sites. Thus it seems to be difficult that $\mathrm{ZnBr}_{4}$ takes six distinguishable orientations.

If cations as a whole are orientationally disordered, Boltzmann's principle leads to $N_{\mathrm{h}} / N_{1}=2.5$, and when methyl groups in a lutidinium ion have disordered sites, $N_{\mathrm{h}} / N_{1}$ is estimated to be 1.6. There is also a possibility of a simultaneous disordering of cations as a whole and methyl groups or cations and anions. In any case, a disordering of cations probably takes place above $327 \mathrm{~K}$ in $(2,6-\mathrm{luH})_{2} \mathrm{ZnBr}_{4}$. This is very interesting, because a single methyl group introduced in a pyridinium ring prevents cations from disorder in (4-piH) ${ }_{2} \mathrm{ZnBr}_{4}$, but two methyl groups do not to prevent the disorder.

\section{Lattice Stability}

$(\mathrm{pyH})_{2} \mathrm{ZnBr}_{4}$ and $(2,6-\mathrm{luH})_{2} \mathrm{ZnBr}_{4}$ show a single order-disorder transition respectively, while no structural phase transition is detected for (4-piH) ${ }_{2} \mathrm{ZnBr}_{4}$ and $(\mathrm{guH})_{2} \mathrm{ZnBr}_{4}$. In other words, a displacive phase transition is not observed for all compounds, although $(\mathrm{pyH})_{2} \mathrm{ZnBr}_{4}$ may undergo such a transition. The temperature variations of NQR frequencies in the four compounds are very monotonous, which contrasts with those in $\left(n-\mathrm{C}_{n} \mathrm{H}_{2 n+1} \mathrm{NH}_{3}\right)_{2} \mathrm{ZnBr}_{4}$ that undergo some structural phase transitions [2]. These facts seem to reflect the stability of crystal lattices in the present system, which can be explained qualitatively in terms of Cochran's theory [20]. 
According to this theory, the lattice instability that leads to structural phase transitions in ionic crystals occurs via a subtle cancellation of the short-range (SR) interaction by the long-range (LR) Coulombic interaction. This can be written schematically as follows:

$$
\omega_{\mathrm{s}}^{2} \propto(\text { SR interaction })-(\text { LR interaction }),
$$

where $\omega_{\mathrm{s}}$ is a soft phonon frequency. For simplicity, we regard the molecular ions as point charges for the Coulombic interaction. Since the LR interaction is inversely proportional to a primitive-cell volume $V$, it is more difficult for a crystal with a larger $V$ to undergo a displacive phase transition. Since a pyridinium ion, a guanidinium ion and so on have a very large size compared with alkali metal ions, the present four compounds have larger $V$ than $\mathrm{A}_{2} \mathrm{BX}_{4}$ compounds with alkali metal ions, many of which compounds are known to undergo successive phase transitions [21]. The fact that the melting temperatures in the four compounds are relatively low is considered to reflect this weak cohesive force. Furthermore, $\mathrm{NH}$...Br hydrogen bonds seem to contribute to the lattice stabilitiy in the present four compounds, too.

In the case of $(\mathrm{guH})_{2} \mathrm{ZnBr}_{4}$, hydrogen bond networks are functioning to prevent cations from disordering. A guanidinium ion has three $\mathrm{NH}_{2}$ groups and all of four bromine atoms in a $\mathrm{ZnBr}_{4}$ tetrahedron are involved in three dimensional hydrogen bond networks connecting cations and anions [17]. Because of this richness in hydrogen bonds, guanidinium ions cannot occupy disordered sites in crystals. An average $\mathrm{NQR}$ frequency at $77 \mathrm{~K}$ in $(\mathrm{guH})_{2} \mathrm{ZnBr}_{4}$ is $60.007 \mathrm{MHz}$, which is lower than those in other

[1] K. Horiuchi, J. Phys. Soc. Japan 63, 363 (1994).

[2] K. Horiuchi and Al. Weiss, J. Mol. Struct. 345, 97 (1995).

[3] Y. Sakiyama, K. Horiuchi, and R. Ikeda, J. Phys.: Condens. Matter 8, 5345 (1996).

[4] H. Ishihara, S.-q. Dou, K. Horiuchi, V. G. Krishnan, H. Paulus, H. Fuess, and Al. Weiss, Z, Naturforsch. 51a, 1027 (1996).

[5] H. Ishihara, S.-q. Dou, K. Horiuchi, H. Paulus, H. Fuess, and Al. Weiss, Z. Naturforsch. 52a 550 (1997).

[6] K. Horiuchi, H. Takayama, S. Ishimaru, and R. Ikeda, Bull. Chem. Soc. Japan 73, 307 (2000). compounds (those in $(\mathrm{pyH})_{2} \mathrm{ZnBr}_{4},(4-\mathrm{piH})_{2} \mathrm{ZnBr}_{4}$, and $(2,6-\mathrm{luH})_{2} \mathrm{ZnBr}_{4}$ are 61.530, 61.050, and $61.423 \mathrm{MHz}$, respectively). This may be due to the effect of hydrogen bonds.

\section{Transition Entropy}

Here we define a sum of transition entropy and fusion entropy as a total entropy change $\Delta S_{\mathrm{t}}$. $\Delta S_{\mathrm{t}}$ in $(\mathrm{pyH})_{2} \mathrm{ZnBr}_{4}, \quad(4-\mathrm{piH})_{2} \mathrm{ZnBr}_{4}, \quad(2,6-\mathrm{luH})_{2}-$ $\mathrm{ZnBr}_{4}$ and $(\mathrm{guH})_{2} \mathrm{ZnBr}_{4}$ are 80, 90, 100, and $70 \mathrm{~J} \mathrm{~K}^{-1} \mathrm{~mol}^{-1}$, respectively. Similar $\Delta S_{\mathrm{t}}$ values of 81 and $86 \mathrm{~J} \mathrm{~K}^{-1} \mathrm{~mol}^{-1}$ are observed in 2-picolinium hexachlorostannate(IV) and hexachlorotellurate(IV), respectively [8]. We can roughly estimate the entropy gains $\Delta S_{\mathrm{p}}$ due to the melting of positional orders in molecular ions to be about $3 R=25 \mathrm{~J} \mathrm{~K}^{-1} \mathrm{~mol}^{-1}$ by Richard's rule, which was originally proposed for compounds made up of atomic ions. Hence $\Delta S_{\mathrm{p}}$ values are presumably smaller than $3 R$ in the present system. In any case, we see that the entropy gains due to the melting of orientational orders are two or three times larger than $\Delta S_{\mathrm{p}}$. This means that in molten salts rotational motios in molecular ions are relatively free compared with translational motions. Differences in $\Delta S_{\mathrm{t}}$ values among $(\mathrm{pyH})_{2} \mathrm{ZnBr}_{4},(4-\mathrm{piH})_{2} \mathrm{ZnBr}_{4}$, and $(2,6-l u H)_{2} \mathrm{ZnBr}_{4}$ are likely to be ascribed to the entropy gains due to the rotational melting in methyl groups.

\section{Acknowledgements}

Two of us (K. H. and H. I.) would like to express our appreciation to Alexander von Humboldt-Stiftung for a fellowship.

[7] K. Horiuchi, H. Ishihara, and H. Terao, J. Phys.: Condens. Matter 12, 4799 (2000).

[8] K. Horiuchi, H. Iwafune, T. Asaji, and D. Nakamura, J. Phys.: Condens. Matter 6, 9075 (1994).

[9] T. Asaji, K. Horiuchi, T. Chiba, T. Shimizu, and R. Ikeda, Z. Naturforsch. 53a, 419 (1998).

[10] K. Yamada, T. Tsuda, C. Holst, T. Okuda, H. Ehrenberg, I. Svoboda, H.-G. Krane, and H. Fuess, Bull. Chem. Soc. Japan 74, 77 (2001).

[11] K. Horiuchi and T. Fukami, Bull. Chem. Soc. Japan 69, 1527 (1996).

[12] S. Gimma, Y. Furukawa, and D. Nakamura, Ber. Bunsenges. Phys. Chem. 88, 939 (1984). 
[13] Y. Furukawa, S. Gimma, and D. Nakamura, Ber. Bunsenges. Phys. Chem. 89, 863 (1985).

[14] Y. Furukawa and D. Nakamura, Bull. Chem. Soc. Japan 59, 2642 (1986).

[15] K. Horiuchi, A. Sasane, Y. Mori, T. Asaji, and D. Nakamura, Bull. Chem. Soc. Japan 59, 2639 (1986).

[16] K. Horiuchi, J. Chem. Soc. Faraday Trans. 89, 3359 (1993).
[17] M. Kubicki and M. Szafranski, J. Mol. Struct. 446, 1 (1998).

[18] H. Terao, private communication.

[19] P. Trouelan, J. Lefebvre, and P. Derollez, Acta Cryst. C40, 386 (1984).

[20] W. Cochran, Adv. Phys. 9, 387 (1960).

[21] "Incommensurate Phases and Dielectrics", ed by R. Blinc and A. P. Levanyuk, North-Holland, Amsterdam (1986). 